\title{
Tratamiento ortodóntico de una maloclusión de clase I con transposición dentaria
}

\section{Orthodontic treatment of a class I malocclusion with dental transposition}

\author{
Andrea Stephanie Silva Bernedo ${ }^{1 \mathrm{a}}$ \\ ID https://orcid.org/0000-0003-4827-9322 \\ ${ }^{1}$ Investigador independiente. \\ ${ }^{a}$ Cirujano Dentista.
}

\section{Resumen}

La transposición dental es el intercambio posicional de dos dientes adyacentes, o el desarrollo o erupción de un diente en una posición normalmente ocupada por un diente no adyacente; siendo el tipo más común de transposición dental el del canino superior y primer premolar. Esta anomalía puede provocar diversos problemas funcionales y estéticos, y por estas razones necesita de un correcto diagnóstico para un tratamiento precoz; que involucra, generalmente, un abordaje multidisciplinario. El objetivo de este artículo es mostrar el abordaje terapéutico usado en un paciente.

Palabras clave: Transposición dentaria, anomalía, diagnóstico.

\begin{abstract}
Dental transposition is the positional exchange of two adjacent teeth, or the development or eruption of a tooth in a position normally occupied by a non-adjacent tooth, the most common type of dental transposition being the upper canine and first premolar. This anomaly can cause various functional and aesthetic problems and for these reasons requires a correct diagnosis for early treatment, which usually involves a multidisciplinary approach. The objective of this article is to show the therapeutic approach that was used for this patient.
\end{abstract}

Keywords: Dental transposition, anomalies, diagnosis.

\section{Introducción}

La transposición dentaria puede ser definida como el cambio en la posición de 2 dientes, adyacentes o no; especialmente con relación a sus raíces en el mismo cuadrante del arco dentario, que se desarrollan y erupcionan en posiciones invertidas y alteran la secuencia normal de la erupción $(1,2)$.

La transposición ocurre, mucho más comúnmente, en el maxilar que en la mandíbula; siendo la transposición unilateral más común que la transposición bilateral, y el lado izquierdo, el más involucrado (3). Entre los muchos tipos de transposiciones, los caninos y premolares superiores son el tipo más frecuentemente reportados (4).

Se denomina transposición completa si tanto la corona como la estructura de la raíz completa de los dientes involucrados se encuentran paralelas en su posición transpuesta.

Se llama transposición incompleta si la transposición es de la corona, pero no de la raíz $(5,6)$. Cuando la transposición es completa la tentativa de reposicionar los dientes afectados en el arco es compleja; se puede causar perjuicio a los tejidos de soporte. La opción de extracción del diente permanente, generalmente el premolar, se torna más atractiva. Las transposiciones dentarias son más frecuentes en el sexo femenino, y el lado izquierdo, generalmente, es el más afectado. Sin embargo, rara vez se observa la aparición simultánea de transposición en ambos arcos, así como en la dentición decidua (7). Factores etiológicos tales como herencia, genética $(8,9)$, intercambio de la posición del desarrollo de brotes dentales, traumatismos, presencia de dientes retenidos (10), pérdida temprana de dientes permanentes, y falta de espacio han sido presentados en 
la literatura del caso (11). La evidencia reciente sugiere que la transposición dental representa una condición multifactorial en la que parecen estar involucrados factores genéticos y ambientales, y las relaciones son complejas (12).

La transposición es una anomalía dentaria poco documentada en la literatura, a pesar de ser conocida desde hace mucho tiempo; probablemente desde inicios del siglo XIX. Por estas razones constituye un desafío para los profesionales que deciden tratarla, debido a su etiología indefinida y a que ocasiona problemas estéticos, funcionales, y por las dificultades en decidir cuál es el tratamiento más indicado (13).

En un reporte de caso publicado en la revista Angle Orthodontist se describe a un paciente con transposición bilateral, uno completo y otro incompleto, involucrando al canino maxilar y al primer premolar (Mx.C.1P). El tratamiento de ortodoncia que se llevó a cabo implicó la corrección de ambas transposiciones; el paciente presentaba, en ambos lados, los caninos deciduos que se extrajeron antes del tratamiento de ortodoncia. En la transposición completa, la tracción fue mesial y ascendente para mover al canino a una posición más apical con un proceso dentoalveolar más amplio para facilitar el intercambio de la corona (14).
En este artículo se trató ortodónticamente un caso de transposición dentaria de canino y primer premolar, sin llevar al canino a su posición, sino manteniéndolo en la posición del primer premolar, y este, en la posición del canino. Vemos que en la literatura se pueden encontrar varios informes sobre transposición de caninos maxilares y primer premolar; aunque muy pocos incluyen procedimientos de tratamiento (15). Se sabe que es un desafío para los profesionales tratar la transposición, debido a su etiología indefinida y a que ocasiona problemas estéticos y funcionales; es por ello, que con este artículo queremos ahondar en el tema y mostrar el tratamiento que se realizó en el paciente.

\section{Reporte de caso}

Paciente masculino de 13 años y 5 meses de edad, de raza mestiza. Acudió con el motivo de consulta: "Un diente me está saliendo arriba". Su estado general de salud era aparentemente bueno, y no presentaba hábitos nocivos para la salud oral.

En el examen clínico intraoral presentaba bajo riesgo de caries, dentición mixta, maloclusión (según la clasificación Angle; de clase I con transposición dentaria y relaciones caninas no registrables), overbite de $15 \%$, overjet de $3 \mathrm{~mm}$, línea media superior desviada $3 \mathrm{~mm}$ hacia la derecha, y discrepancia negativa de $-8 \mathrm{~mm}$ en maxilar superior y-2mm en inferior (Fig. 1).

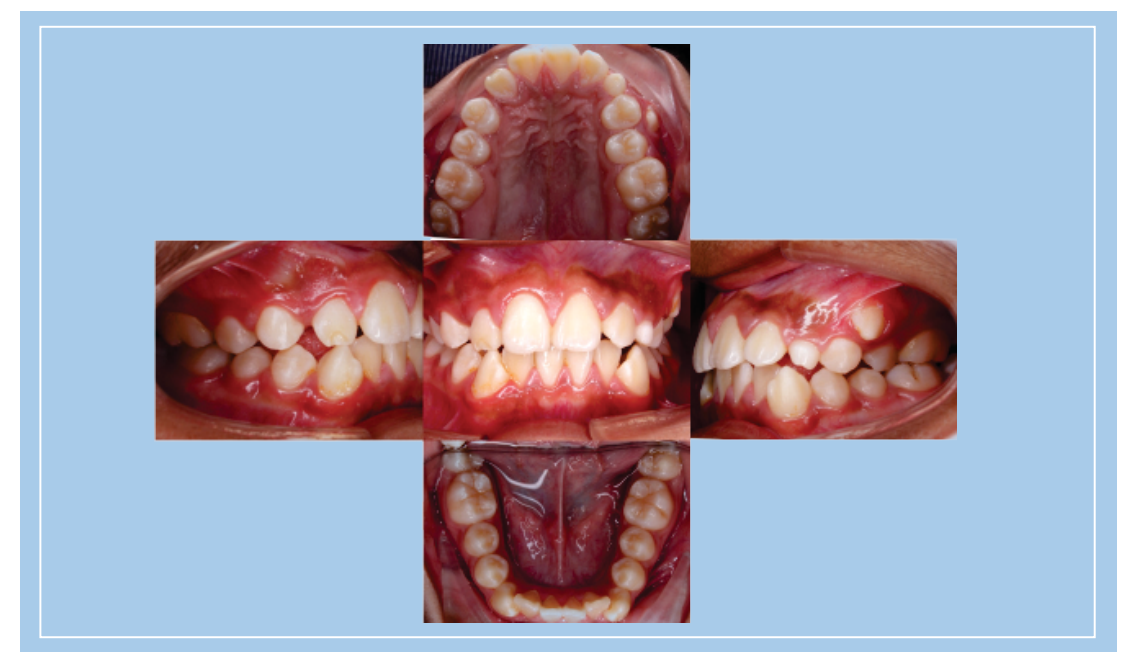

Figura 1. Fotografías intraorales.

La radiografía panorámica mostraba la transposición dentaria de canino y primer premolar superior izquierdo y la presencia del canino deciduo izquierdo; al igual que la presencia del canino superior derecho retenido (Fig.
2). En las medidas cefalométricas se observa una relación esquelética de clase I con ángulo normodivergente con crecimiento a predominio horizontal y un perfil convexo (Fig. 3). 


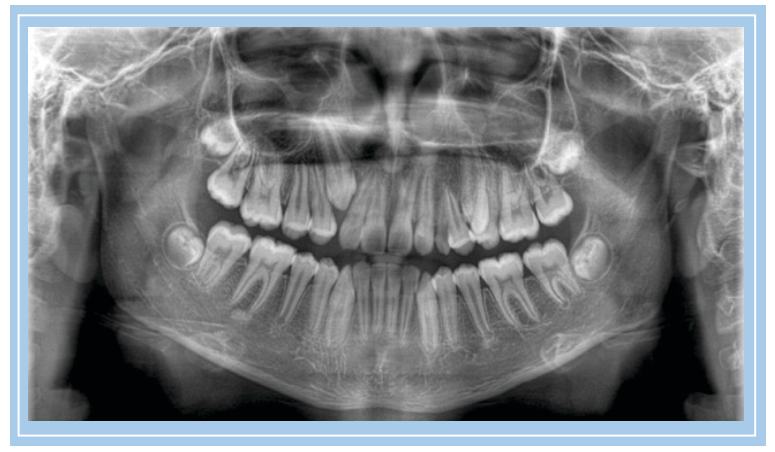

Figura 2. Radiografía panorámica.

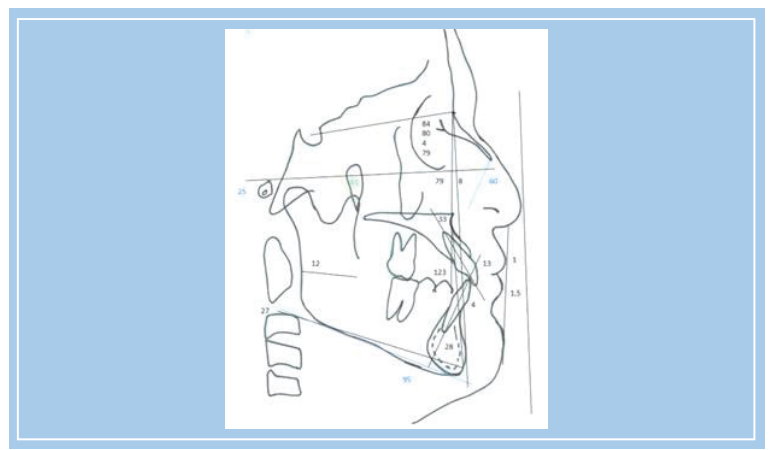

Figura 3. Trazado y medidas cefalométricas iniciales.

Después del estudio del caso se optó por colocar 2 miniimplantes en la zona del paladar de $8 \times 1.5 \mathrm{~mm}$ para instalar un hyrax de $9 \mathrm{~mm}$ soldado a las bandas de los primeros molares superiores. En el transcurso de dos semanas de activaciones, $1 / 4$ de vuelta por la mañana y $1 / 4$ de vuelta por la noche, se logró ganar espacio (Fig. 4). Luego se retiró la pieza 63 y se instaló los brackets MBT con slot $0.018 \times 0.022$ con arco niti 0.012 . El plan de tratamiento consistía en mesializar la pieza 24 hasta que llegue a contactar con distal de la pieza 22 y así tener el espacio para que la pieza 23 descienda y ocupe el lugar del primer premolar.

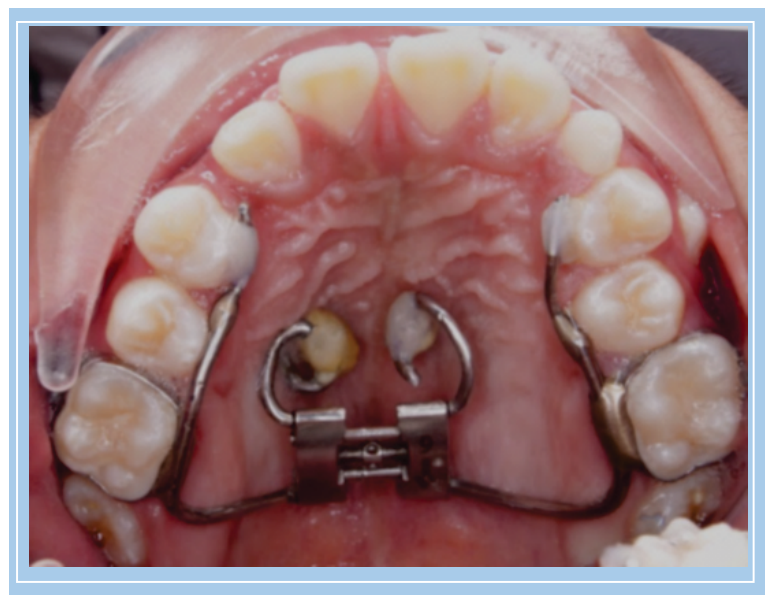

Figura 4. Hyrax con miniimplantes.
Se fabricó un cantilever logarítmico con alambre TMA 0.017 " x 0.025 " que salía del tubo accesorio de la pieza 26 , y que se activó amarrándolo con alambre de ligadura $0.09 \mathrm{~mm}$ al bracket de la pieza 24 por 5 meses, hasta que se llegó a la posición deseada. A la vez se instaló una placa hawley con tornillo de expansión en el maxilar inferior, con activación de $1 / 4$ de vuelta por la mañana y $1 / 4$ de vuelta por la noche, por unos 6 meses (Fig. 5 a, b, c). Posteriormente se procedió al retiro del cantilever logarítmico. Instalamos un alambre niti 0.014 " con bypass entre las piezas 14 y 25 y colocamos un bracket en la pieza 23 para que con un cantilever se logre la extrusión necesaria (Fig. 5d).

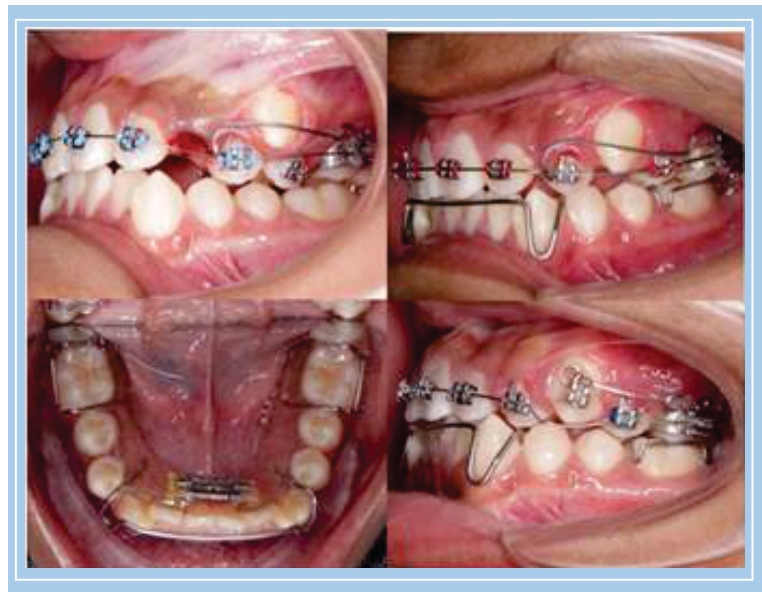

Figura 5. (a) Cantilever logarítmico al inicio, (b) Cantilever logarítmico después de 5 meses de activación, (c) Placa de Hawley inferior con tornillo de expansión, (d) Cantilever de extrusión.

Se incorporó un resorte abierto entre las piezas 14 y 12 . Se pegó un botón en la pieza 13, que se encontraba impactada, para poder colocar un cantilever de extrusión con TMA 0.017 " x 0.025" que sale del tubo accesorio del primer molar superior derecho (Fig. 6). Después de 6 meses se pudo pegar el bracket en la pieza 13 y pasar un arco corrido niti 0.016 " en el maxilar superior. Se retiraron los miniimplantes y el hyrax dejando un ATP como contención, luego se instaló la aparatología fija en el maxilar inferior con alambre niti 0.012 ", niti 0.016 ", y se continuó la secuencia de arcos, en las dos arcadas, con arcos de acero $0.016 ", 0.016 " \mathrm{x}$ 0.022 ". Se repegaron los brackets de las piezas dentales 34, 35, 43 para mejorar la oclusión hasta llegar a terminar de alinear y nivelar con arcos ideales que se confeccionaron con alambre de acero 0.017 " x 0.025 ". El tratamiento finalizó después de un año y 5 meses. 


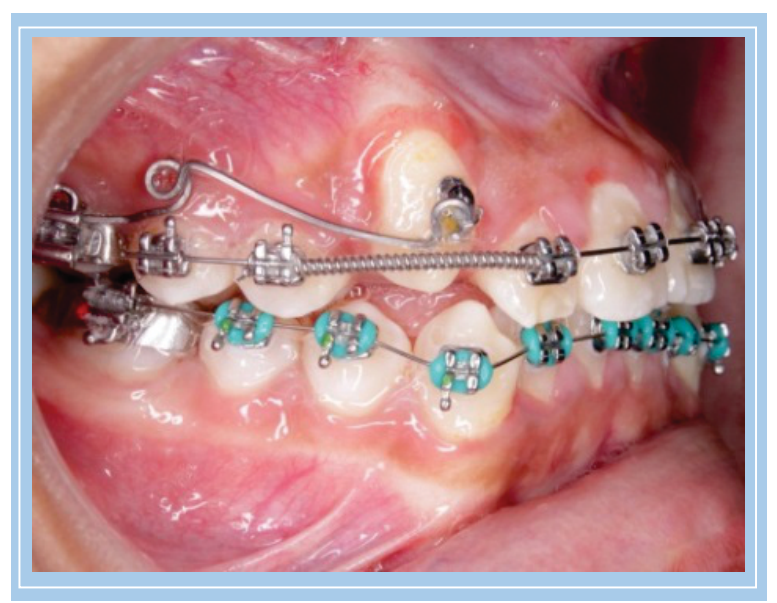

Figura 6. Cantilever de extrusión en la pieza 13 impactada.

Teniendo en cuenta la complejidad del caso; los registros durante este tratamiento muestran un buen resultado, porque se cumplieron los objetivos de tratamiento en un corto tiempo: se mantuvo la clase I molar; se llegó a la clase I canina; y se resolvió la desviación de la línea media superior (Fig. 7).

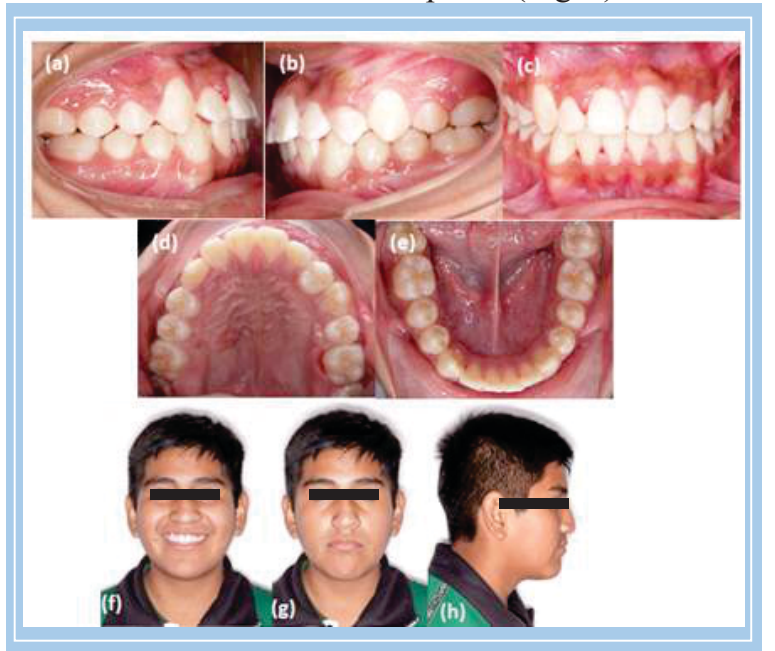

Figura 7. Fotografías intraorales: (a) lateral derecho; (b) lateral izquierdo; (c) frontal; (d) oclusal superior; (e) oclusal inferior. Fotografías extraorales: (f) fotografía de frente en sonrisa; (g) fotografía de frente; (h) fotografía lateral.

\section{Discusión}

Comúnmente, en la transposición de canino con el primer premolar, el canino se posiciona en dirección mesiovestibular entre el primer y segundo premolar, mientras que el primer premolar está frecuentemente inclinado distalmente en mesiopalatoversión. Además, es frecuente observar la presencia de caninos deciduos que ocasionan una restricción temporal de espacio en el arco dentario (16).

Cuando la transposición es completa, la tentativa de reposicionar los dientes afectados en el arco es compleja; se puede causar perjuicio a los tejidos de soporte. La opción de extracción del diente permanente, generalmente el premolar, se torna más atractiva; sobre todo si los dientes afectados por la transposición presentan caries o poco soporte periodontal, así como ante la presencia de una discrepancia hueso-diente negativa severa o de un perfil protruso (17). Es por esto que se optó, como tratamiento, la extracción del canino deciduo y la reubicación del premolar como canino, y de este, como premolar. Dado que el paciente presentaba una clase I molar y un perfil aceptable, no se optó por extracciones.

Podemos concluir que después de evaluar las características del tratamiento para la transposición dentaria que presenta el paciente se optó por el mejor abordaje terapéutico tanto para la estética como para el corto tiempo de tratamiento. Los registros finales de este paciente presentaron el acabado adecuado del tratamiento en una relación de clase I. Se recomendó al paciente hacer una interconsulta con un periodoncista para realizar un injerto de encía en la pieza retenida 13 y mejorar el festoneado del cuadrante.

\section{Referencias bibliográficas}

1. Peck L PSAY. Maxillary canine-first premolar transposition, associated dental anomalies and genetic basis. Angle Orthod Appleton. 1993;63:99-10.

2. Wake M HKLJ. Teething and tooth eruption in infants: A cohort study.. Pediatrics. 2000;106(6):1374-1379.

3. Shapira YyMK. Transposiciones dentales maxilares : características características y acompañamiento de anomalías dentales. J Orthod Dentofacial Orthop 2001. 119: 127 134.

4. Chattopadhyay AyKS. Transposición de dientes y etiología genética.. Ortodoncia de ángulos 1996. 66: $147-152$.

5. Shapira YyMK. Transposición de los dientes: revisión de la literatura y las consideraciones de tratamiento. Ortodoncia de ángulo 1989. 59: $271-276$. 
6. Shapira YyMK. Transposiciones dentales maxilares : características características y acompañamiento de anomalías dentales. J Orthod Dentofacial Orthop 2001. 119: 127 - 134.

7. Peck L PSAY. Maxillary canine-first premolar transposition, associated dental anomalies and genetic basis. Angle Orthod Appleton. 1993;63:99-109.

8. Chattopadhyay A SKT. Transposition of teeth and genetic etiology.. Angle Orthod. 1996;66:147-152.

9. Peck S PL. Classification of maxillary tooth transpositions. Am J Orthod Dentofacial Orthop. 1995; 107:505517.

10. Laptook T SG. Transposición canina: enfoques para el tratamiento. J Am Dent Assoc. 1983 ; 107: $746-748$.

11. Laptook T SG. Canine transposition-approaches to treatment.. J Am Dent Assoc. 1983;107:746-748.
12. Ely NJ SMCM. La transposición dental como trastorno de origen genético. Eur J Orthod. 2006 ;28: 145-151.

13. Costa LED DRPMBRBR. Transposição dentária: estudo de prevalência em escolares na cidade de João Pessoa, PB. Pesq Bras Odontoped Clin Integr. 2010;10:107-12.4.. Praxedes Neto OJ, Caldas SGFR, Medeiros AM.

14. Lorente C. LP,PVM,ECyLT. Maxillary CanineFirst Premolar Transposition in the Permanent Dentition. Angle Orthod.2019.

15. Mader CaJLoth. J Am Dent Assoc 1979. 98:412-413.

16. Mattos BSC CJMMAA. Tooth transposition a literature review and a clinical case. Braz J Oral Sci. 2006;5:953-7.

17. Filho LC CMNJ. Tratamento da transposição de canino e premolar superior unilateral: abordagem por meio de mecânica segmentada. Rev Clín Ortodon Dent Press. 2007;6:13-7.
Correspondencia:

ansil44@hotmail.com
Fecha de recepción : 27 de febrero de 2020

Fecha de aceptación : 09 de mayo de 2020 